\title{
Calcium Therapy.
}

THE subject of calcium therapy was discussed at the recent meeting at Edinburgh of the Section of Pharmacklofynand Therapeutics of the British Medical Asfoctation. Such a discussion must, of necagsite, cover a certain amount of ground in which the interest is primarily cilnical; nevertheless it furnishes an intereing summary of the present state of knowledge of darcilum metabolism.

Evidently the interest of those working on the subject has, for the moment, three main foci, namely, the elucidation of the actual physical and chemical conditions in which calcium circulates in the blood and exists in the tissues; the point in the system of bones, blood, and tissues, at which the parathyroid hormone exerts its influence; and the relationships existing between, on one hand, ionic calcium, and on the other, the negative ions-chiefly, of course, $\mathrm{Cl}^{\prime}$ - in tissues and fluids.

In spite of the adverse criticism which they have received, Vines's earlier results seem to have shown quite clearly that about 60 per cent. of the blood calcium is in a state which differs, chemically, from the remaining 40 per cent. Other workers, using different methods, have extended and amplified this conclusion. It appears that, of the $10 \mathrm{mgm}$. present in 100 c.c. of normal serum, $6 \mathrm{mgm}$. is diffusible through a collodion membrane, while $4 \mathrm{mgm}$. is combined, perhaps with protein or lipoid, in such a way as to be non-diffusible. While interest, for the moment, centres round the diffusible form, there is evidence that the non-diffusible, no less than the diffusible, is liable to variation in such circumstances as parathyroidectomy, or the administration of parathyroid extract.

Of the diffusible calcium, probably $2 \mathrm{mgm}$. or so is in ionic form. It has been suggested that the remaining $4 \mathrm{mgm}$. may be combined with some substance of properties comparable, in this connexion, to those of citric acid. Quite probably, all three forms (if there be but three) are in equilibrium : variations in the amount of any one form must be reflected in variations in that of the others. It was, for example, pointed out that in prolonged diffusion experiments actually more than 60 per cent. of the total calcium passes into the diffusate, owing to the breaking up of the diffusible into the non-diffusible form.

Certain views ${ }^{1}$ concerning the relationship of the parathyroids to calcium metabolism, implied rather than explicitly stated during the discussion, may be put into a fairly definite form.

It has been clearly shown that injection of parathyroid hormone increases blood calcium without increasing absorption or diminishing excretion of the metal by the alimentary canal, since the typical rise can be obtained in anæsthetised, eviscerated animals. 'This rise must, therefore, occur at the expense of calcium either of the bones or of soft tissues,

1 A similar view has been expressed to the writer, independently, by Mr. Hoyle, of the Pharmacological Laboratory, Cambridge. or of both. The hormone, in fact, must mobilise calcium from some reserve store. It appears that in certain cases of so-called ' renal infantilism'-a state in which nephritic changes accompany failure in body development-there occurs both a high level of blood phosphate, and a hypercalcæmia, associated with severe rachitic changes in the bones. A case was also described in which the bony changes known as 'osteitis fibrosa' were accompanied by a blood calcium level of $17 \mathrm{mgm}$. per cent., and the appearance of very definite adenomatous tumours of the parathyroids. It has been stated that young animals, fed on a calcium-poor diet, show definite parathyroid hypertrophy.

Taken together, these observations seem strongly to suggest that, whatever the immediate source of the blood calcium, any prolonged rise in its amount results in the draining of the element from the bones, and that the action of the parathyroid hormone is in favour of such a transference. A consideration of the relative amounts of calcium in the bones and the circulating fluid makes it obvious that only after a prolonged demand would any measurable effect be produced on the relatively enormous calcium store of the bones. It is well known that cardiac and nervous tissues are extremely sensitive to $\mathrm{Ca}{ }^{*} / \mathrm{K}^{\prime}$ balance, and it is difficult to imagine that any marked or prolonged rise in blood ealcium would take place entirely at the expense of the soft tissues. Such data as are available suggest that calcium is concerned with the maintenance of cell surface structures ; it is hard to picture such structures parting with calcium without the occurrence of marked disturbances.

The evidence concerning the point of action of vitamin $D$ is, at present, meagre, and the subject still obscure. Some observations suggest that it promotes calcium absorption, possibly by some influence on the $p \mathrm{H}$ of the intestinal tract. Obviously any agency tending to shift the reaction to, or to retain it at, the acid side of neutrality would favour the existence of soluble rather than insoluble calcium compounds. Such an explanation would, however, place the vitamin in the same category as a phosphaterich diet, which increases the rickets-producing power of a calcium-poor diet by hindering the absorption of the element. Evidence of the action of vitamin $D$ on the mechanisms of bone formation, such as the phosphate esterase of Robison, is so far lacking.

Little light can at present be shed on the difficult question of the relationships of $\mathrm{Ca}^{*}$ and $\mathrm{Cl}^{\prime}$ ions, and of $p \mathrm{H}$, in blood and tissues. It is suggested that the treatment of certain conditions, such as the odema of nephritis, by calcium chloride depends as much on the readjustment of the $\mathrm{Na}^{\circ} / \mathrm{Cl}^{\prime}$ ratio as on any effect of calcium per se; it is well known that tetany is favoured by an increase, and tends to be relieved by a decrease of the alkali reserve, though Collip has shown that both in tetany and in hypercalcæmia there is a terminal uncompensated acidosis. $\quad$ E. $\mathrm{H}$.

\section{Congress of the History of Medicine.}

THE sixth Inteptitional Congress of the History of Madif o low has held during the week July 18-23 ufd the presidency of Dr. J. G. de Lint, lecurgr fon the history of medicine in the University of Hey $\mathrm{n}$. The meetings during the first three days were hold at Leyden and the rest of the week at Amsterdam. The attendance was larger than at any previous congress organised by the International Society of the History of Medicine. No less than twenty countries, among which Germany and Austria figured for the first time, were represented, so that the Congress, as many of the speakers remarked, was for the first time really international. Owing to the simultaneous annual meeting of the British Medical Association at Edinburgh, where a section of the history of medicine had been inaugurated, only a few British representatives, including Sir D'Arcy Power, Dr. Charles Singer, and Dr. J. D. Rolleston were present.

No. 3020 , Vot. 120 j 